\title{
As categorias de tempo, aspecto, modo e modalidade em Boróro
}

\author{
Lidiane Szerwinsk Camargos ${ }^{1}$
}

\begin{abstract}
Resumo
Neste artigo apresento uma análise alternativa às propostas de Crowell (1979, Viana (2003a, b) e Nonato (2008) sobre as categorias de tempo, modo, modalidade e aspecto na língua Boróro (Tronco Macro-Jê, Rodrigues, 1986). A análise se baseia principalmente nos trabalhos teóricos de Comrie (1976) e Chung e Timberlake (1985) sobre tempo, nos trabalhos de Vendler (1957), Comrie (1976), Chung e Timberlake (1985) e Desclés e Guentchéva (1997) sobre aspecto e Aktionsart, nos trabalhos de Jespersen (1924), de Chung e Timberlake (1985), e de Palmer (1986) sobre modo e modalidade.
\end{abstract}

Palavras-chave: Boróro; tempo; modo; aspecto; modalidade.

\begin{abstract}
In this paper I present an alternative to the analyses proposed by Crowell (1979), Viana $(2003 \mathrm{a}, \mathrm{b})$ and Nonato $(2008)$ on the categories of tense, mood, modality, and aspect in the Bororo language (Macro-Jê stock, Rodrigues 1986). The analysis is mainly based in the theoretical works by Comrie (1976) and by Chung and Timberlake (1985) on tense, on the tworks by Vendler (1957), Comrie (1976), Chung and Timberlake (1985), and Desclés and Guentchéva (1997) on aspect and Aktionsart, as well as on the works by Jespersen (1924), Chung and Timberlake (1985), and Palmer (1986) on mood and modality.
\end{abstract}

Keywords: Boróro, tense, mood, aspect, modality.

\section{Introdução}

Neste estudo, mostro que as diferentes análises dos morfemas re e modi do Boróro, como a de Crowell (1979), que concebe o primeiro como expressão de aspecto e o segundo como expressão de tempo, a de Viana (2003a, b), que trata o primeiro como aspecto e o segundo como modo, e a de Nonato (2008), que trata o primeiro como modo e o segundo como tempo, se devem à dificuldade de encontrar, em outras línguas, correlatos com as funções que esses morfemas exercem na gramática Boróro. Algumas das perguntas que podem ser feitas a respeito do morfema re são: "Por que razão uma dada língua marcaria todas as suas construções em que se indaga sobre

\footnotetext{
${ }^{1}$ Professora da Universidade Federal de Rondônia, Campus Ji-Paraná, pesquisadora do Laboratório de Línguas Indígenas da Universidade de Brasília.
} 
um fato ou em que se declara algo?" "Por que essa marca ora se combina com predicados, ora com o agente sintático?" "re e modi são expressões de uma mesma categoria gramatical ou não?" "Se não, como fundamentar uma hipótese contrária?”.

Procuro responder a essas perguntas com base nos dados de Colbacchini e Albisetti (1942), Crowell (1979), Viana (2003a) e Camargos (2006, 2007, 2009, notas de campo). Argumentarei que re e modi são expressões de categorias distintas, fundamentada no simples fato de que o segundo só ocorre em estruturas marcadas pelo primeiro, que ocorre de forma independente. Finalmente, mostrarei que a análise aqui apresentada desafia as análises precedentes com contraexemplos.

\section{Algumas visões sobre as categorias de tempo, aspecto, modo e modalidade}

\subsection{Tempo}

É fato bem conhecido que a categoria "tempo" não é expressa por meio de flexão em todas as línguas. Tradicionalmente essa categoria tem sido referida como aquela que localiza os eventos de fala na linha temporal. Comrie (1976:4)² define tempo linguístico como algo que “... relaciona o tempo da situação referida a algum outro tempo, normalmente o momento da fala”. Para Chung e Timberlake (1985:203), o tempo linguístico “... situa o evento no tempo, comparando a posição das bordas em relação ao tempo locus". As definições da categoria tempo linguístico naturalmente concebem uma linha temporal e dois tempos, um tempo locus e um tempo relativo. $\mathrm{O}$ tempo locus varia de acordo com a experiência que cada cultura desenvolve na sua realidade, da mesma forma que variam os tempos relativos. Para algumas culturas a distinção é binária, mas há culturas que dividem a linha temporal em vários tempos em que ocorrem os eventos e os processos.

\subsection{Aspecto e Aktionsart (modalidade de ação)}

Tanto aspecto como tempo têm sido associados ao verbo, de forma que é comum falar-se de tempo e de aspecto verbal. Por outro lado, há autores que estendem a noção de aspecto também a predicados mais nominais. Aspecto relaciona-se com a estrutura interna dos eventos e processos, mas também pode relacionar-se a um estado ou a uma situação estática. Há línguas em que

\footnotetext{
${ }^{2}$ Minha tradução.
} 
nomes predicam como nas línguas Tupí-Guaraní (cf. Rodrigues 1996). Em línguas como essas, pode-se dizer 'comecei a (ficar) branca', em que o tema para branco pode combinar-se com o sufixo inceptivo ipi.

Considerando a existência de línguas em que as noções passaram historicamente a ter uma relação íntima com os temas verbais núcleos de predicados, situações em que passaram a ser obrigatórias, vários linguistas propuseram a distinção entre aspecto e Aktionsart (ou modalidade de ação). Aspecto então fica restrito a algo mais verbal, enquanto que Aktionsart ou modo de ação corresponde à expressão aspectual mais leve, ainda percebida pelos falantes de uma língua como algo mais lexical.

A noção de aspecto é vista, geralmente, segundo duas tradições distintas, a eslava e a ocidental. Para a tradição eslava, o aspecto relacionase à oposição entre perfectivo e imperfectivo, bem arraigada nas línguas eslavas. Já para a tradição ocidental, essa noção relaciona-se às categorias que marcam as diferenças entre os eventos verbais.

Vendler (1967:143) propôs um esquema de classificação verbal em quatro classes, defendendo que distinções verbais tais como processos, estados, disposições, ocorrências, tarefas, achievements, entre outras, não podem ser feitas somente em termos de tempo, embora o tempo seja uma categoria crucial. Outros fatores, segundo o autor, devem ser considerados, como a presença ou ausência de um objeto, condições, estado da arte das coisas.

Em sua classificação, Vendler (1967:149) distingue estado, atividade, accomplishments e achievements.

(...) the concept of activities calls for periods of time that are not unique or definite. Accomplishements, on the other hand, imply the notion of unique and definite time periods. In an analogous way, while achievements involve unique and definite time instants, states involve time instants in an indefinite and nonunique sense.

Segundo Chung e Timberlake (1985:213), “...aspecto caracteriza a relação de um predicado com o intervalo de tempo dentro do qual ocorre". De acordo com os autores essa definição destina-se a incluir dois tipos de relação:

- 1) predicados descrevem estados, situações, propriedades, entre outros, que podem permanecer ou não ser constantes, ao longo do tempo. A noção de mudança é central ao aspecto. 
- 2) um evento é composto de um predicado e de algum intervalo de tempo selecionado por falantes, que qualifica as bordas do evento.

Comrie (1976:9) considera o aspecto como uma categoria gramatical que pode ser expressa por meio da morfologia flexional ou por meio de perífrases. Contudo, esse autor estabelece duas distinções para as noções de Aktionsart (modalidade de ação) e de aspecto:

Distinction between aspect and aktionsart is drawn in at least the following two quite different ways. The first distinction is between aspect as grammaticalisation of the relevant semantic distinctions, while aktionsart represents lexicalisation of the distinctions, irrespective of how these distinctions are lexicalized; this use of aktionsart is similar to the notion of inherent meaning (...). The second distinction, which is that used by most Slavists, and often by scholars in Slavonic countries writing on other languages, is between aspect as grammaticalisation of the semantic distinction, and aktionsart as lexicalization of the distinction provided that the lexicalization is by means of derivational morphology.

Na concepção de Desclés e Guentchéva (1997:146), o aspecto é “...une verbalisation de la perception interne de la situation temporalisée". De acordo com esses autores, as categorizações que esta percepção implica são mais primitivas e mais frequentemente gramaticalizadas que as modalidades de ação. Considerando as relações entre as formas e os significados dessas formas, percebe-se que as formas gramaticalizadas são geralmente menos transparentes que as formas lexicais. Assim, Desclés e Guentchéva se baseiam em dois critérios: (i) a gramaticalização mais ou menos forte; (ii) a maior ou menor transparência do significado codificado pelas unidades linguísticas (ou seja, as formas).

Sintetizando, o aspecto aparece fortemente gramaticalizado e as formas que o exprimem são em geral relativamente pouco transparentes, enquanto que as modalidades de ação são mais fracamente gramaticalizadas; com grande frequência elas são somente lexicalizadas e os significados que elas exprimem são em geral mais transparentes.

\subsection{Modo e modalidade}

Enquanto as modalidades são consideradas como de caráter mais subjetivo e com a função de indicar contrastes em verbos e categorias associadas a eles, o modo é visto de uma maneira geral como uma categoria 
que expressa distinções sintáticas e semânticas associadas aos paradigmas verbais (Crystal 1988:174).

Veremos agora algumas definições propostas para essas categorias.

Chung e Timberlake (1985:241) definem modo como caracterizador da atualidade (isto é, da realidade).

(...) Mood characterizes the actuality of an event by comparing the event world(s) to a reference world, termed the actual world. An event can simply be actual (more precisely, the event world is identical to the actual world); an event can be hypothetically possible (the event world may be imposed by the speaker on the addressee; and so on). Whereas there is basically one way for an event to be actual, there are numerous ways that an event can be less than completely actual.

Para Palmer (1986:21) a diferença entre modo e modalidade está relacionada à morfologia verbal:

First, the term 'mood' is traditionally restricted to a category expressed in verbal morphology. It is formally a morphosyntactic category of the verb like tense and aspect, even though its semantic function relates to the contents of the whole sentence. $[\ldots]$

Modality is not expressed in all languages within the verbal morphology. It may be expressed by modal verbs (which are at least still within the verbal element of the sentence) or by particles which may well be quite separate from the verb.

Palmer (1986) definiu a modalidade como a gramaticalização das atitudes e opiniões (subjetivas) do falante. O autor distinguiu modalidade epistêmica de modalidade deôntica e suas subcategorias. A modalidade epistêmica relaciona-se com as noções de possibilidade e necessidade e envolve também o grau de compromisso do falante com o que ele diz, incluindo, dessa forma, os juízos próprios e o tipo de garantia que ele tem para o que ele diz (Palmer 1986:51). A modalidade deôntica relaciona-se às modalidades como contendo um elemento de vontade (Palmer 1986:96).

Jespersen (1924:313) tratou distintamente as categorias de modo e de modalidade. Modo, segundo este autor, é uma categoria sintática, enquanto modalidade é uma categoria nocional. Este mesmo autor apresentou uma lista de categorias de modalidade que expressam ideias puramente nocionais e observou que as categorias frequentemente se sobrepõem e que alguns termos 
que ele mesmo incluiu nas listas são questionáveis. A lista tem duas subdivisões, a que contém elementos de vontade (1) e a que não inclui esse elemento (2).

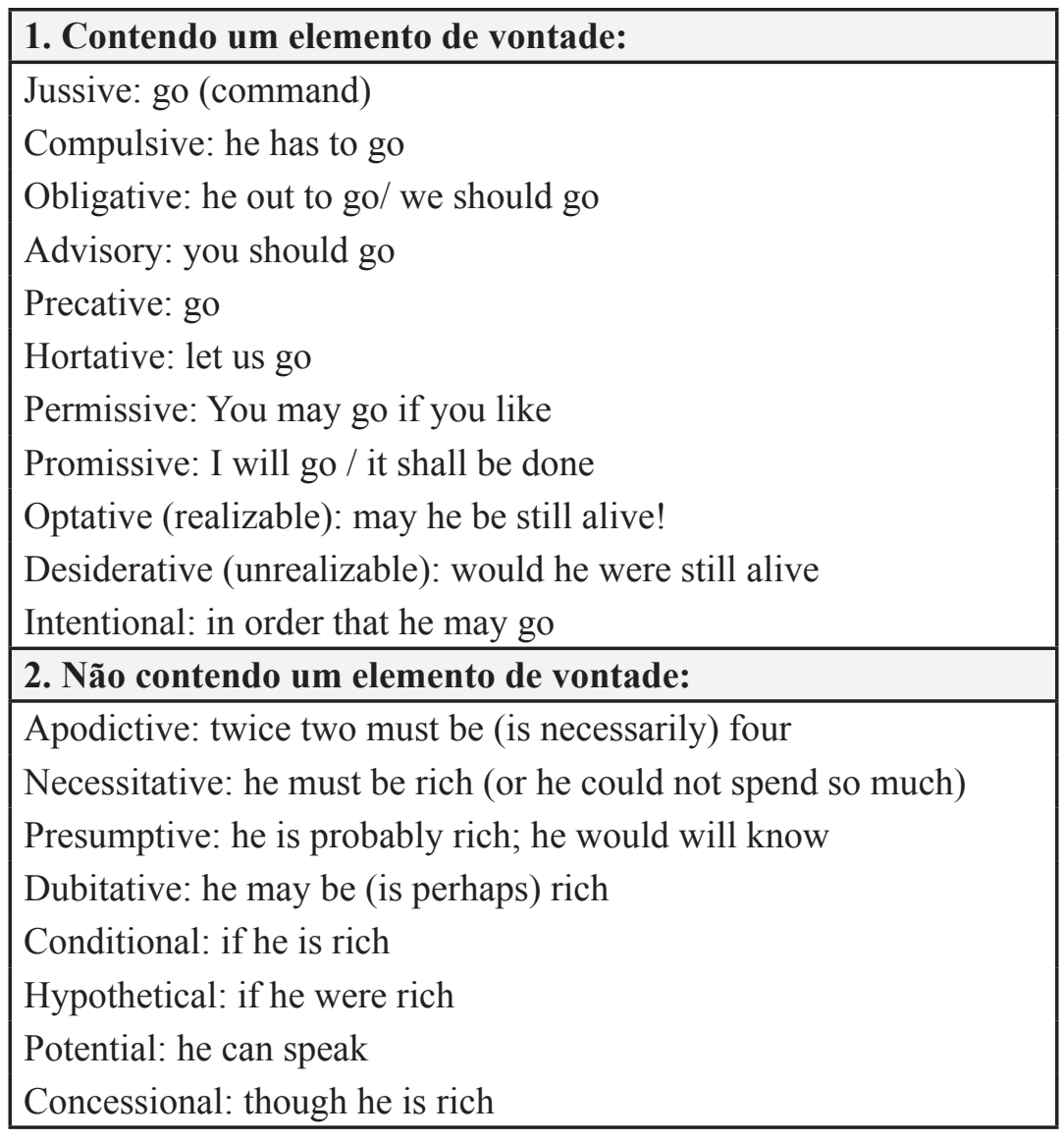

Quadro 1 - Jespersen (1924:320)

\section{Análises precedentes de expressões de tempo, modo e aspecto em Boróro 3}

\subsection{A análise de Crowell}

Segundo Crowell (1979:86), a língua Boróro exprime tempo, modo e aspecto. Entretanto, Crowell refere-se a todas elas pelo mesmo nome aspecto:

\footnotetext{
${ }^{3}$ Abreviaturas: ASSERT $=$ assertivo; CAUS $=$ causativo; DESID $=$ desiderativo; HAB $=$ habitual; IMP = imperativo; IND = indicativo; INF = infinitivo; $N E G$ = negativo; $N L Z=$ nominalizador; PROG = progressivo; $\mathrm{PROJ}=$ projetivo; $\mathrm{R}=$ relacional; $\mathrm{REL}=$ relativo; $\mathrm{REPORT}=$ reportativo; TER $=$ terminativo-recente; $1 \mathrm{SG}=$ primeira do singular; $2 \mathrm{SG}=$ segunda do singular; $3 \mathrm{sg}=$ terceira pessoa singular; INCL = inclusiva; $2 \mathrm{PL}=$ segunda pessoa plural; $3 \mathrm{PL}=$ terceira pessoa plural; $1 \mathrm{~s}=$ primeira do singular; $2 \mathrm{~s}=$ segunda pessoa singular; $3 \mathrm{~S}=$ terceira do singular; $3 \mathrm{p}=$ terceira pessoa plural; $2 \mathrm{p}=$ segunda pessoa plural; $1 \mathrm{PI}=$ primeira pessoa inclusiva.
} 
"This does not mean that tense and mode are any less involved than aspect, but just that I am using aspect to cover all three".

Para esse autor, as noções aspectuais são realizadas por meio de sufixos, os quais ocorrem seguindo o sujeito agentivo em orações que têm agentes e seguindo o verbo em orações sem agentes. A língua Boróro apresentaria, assim, os seguintes aspectos nas orações independentes: recente, incerto, neutro, hipotético, estativo e iterativo.

\section{Recente}

O aspecto recente aponta, segundo Crowell (1979:87), para uma ação ou estado do verbo no tempo presente ou no passado recente, mas sem realização morfológica. A não escolha do aspecto recente não indica, contudo, que a ação ou o estado não aconteceram no presente ou no passado recente.
kade-di
$\emptyset$
cortar-NOMINAL
(1) karo
peixe
RECENTE
'o peixe estava sendo cortado (ou foi cortado recentemente)'
(Crowell 1979:87)

\section{Incerto}

$\mathrm{O}$ aspecto incerto é realizado pelo sufixo -rau, quando este precede imediatamente o neutro -re, e pelo sufixo - ru, nos outros contextos (Crowell 1997:87).
(2) e-mago-
ru-
nire
3PL-falar-
INCERTEZA-
ESTATIVO
'eles provavelmente estão falando' (Crowell 1979:88)

\section{Neutro}

$\mathrm{O}$ aspecto neutro é marcado pelo morfema -re. Quando nem o aspecto imperativo, nem o aspecto recente é selecionado, deve haver uma escolha entre o neutro e o estativo.

\section{(3) imedi maragodi re}

homem trabalhar- NEUTRO

'o homem está trabalhando (ou trabalhou)' (Crowell 1979:88)

Crowell observa que quando ocorre o aspecto neutro, o aspecto hipotético pode co-ocorrer com este na mesma estrutura. Se o aspecto neutro é escolhido, mas não hipotético, a sentença fica no presente ou no passado, 
e a distinção é feita pelo contexto ou por sintagmas temporais. Ainda, para o autor, "como o próprio nome implica, este aspecto traz poucas informações em si, exceto em contraste com outros aspectos" (Crowell 1979:89).

\section{Hipotético}

O aspecto hipotético é realizado por modi, que precede o neutro. Se nada ocorrer entre o hipotético modi e o neutro -re, resulta a forma -mëde. Crowell observa que o hipotético não é mutuamente exclusivo com outros aspectos, mas que o neutro -re pode co-ocorrer com eles (Crowell 1979:90).

\section{(4) $u$-tu-mëde}

3SG-ir-HIPOTÉTICO+NEUTRO

'ele foi provavelmente' (Crowell 1979:90)

Se, contudo, a sua realização se dá por meio ou de ambos ou de dois traços que podem intervir entre o hipotético e o neutro, a forma permanece -mëde -re, ou -ie, quando o aspecto infinitivo é selecionado. As características que podem ocorrer entre o hipotético e o neutro são indireto e negativo (Crowell 1979:91).

(5) u-tu-mëdi-ka-re $u$-tu-ka-re.

'ele provavelmente não foi'. 'ele não foi'.

(6) u-tu-mëdi-ka-ie '(alguém relatou isso) ele provavelmente não foi' $u$-tu-ka-ie '(alguém relatou isso) ele não foi'.

(7) $u$-tu-mëdi-ie '(alguém relatou isso) ele provavelmente foi'. $u-t u-i e$ '(alguém relatou isso) ele foi'

Como função, o hipotético indica a falta de efetividade ou de realidade. É usado em expressões do tempo futuro, declarações de possibilidade ou de falta de certeza e em advertências.
(8) e-mëde
kuiada kadë
3PL- HIPOTÉTICO+ NEUTRO milho cortar
'eles vão cortar o milho (Crowell 1979:92)

O autor considera ainda a possibilidade de o hipotético ser parte de um sistema que contém o neutro e o estativo, uma vez que em ocorrências nãonegativas e em discurso não-direto ele aparece e ocupa o mesmo lugar de outros aspectos, sendo mutuamente exclusivo com estes. 


\section{Estativo}

Quando não ocorre o aspecto neutro, ocorre o estativo -nire. As declarações com o aspecto estativo vão além de uma declaração evidente da existência de uma ação ou estado para descrever uma situação geral, na qual uma única ação representa ou uma parte ou a qualidade essencial de alguma coisa. Com verbos contendo uma qualidade durativa inerente, tais como 'pescar' e 'chover', o estativo denota um estado contemporâneo, enquanto o neutro denota o evento apenas como evento, sem qualidades de estado (Crowell 1979:95).

(9) bibiti-re

chuva-NEUTRO

'está chovendo (ou choveu)' (Crowell, 1979, p.95).

Com o estativo -nire, a oração descreve um estado geral envolvido; isto é, diz que está ou esteve chuvoso. O estativo pressupõe um eventual fim para a ação, enquanto o neutro não (Crowell 1979:96).

\section{(10) bibiti-re wëe meri jamedi-dzi \\ chover-NEUTRO aqui dia todo-REFERENTE}

'chove aqui todo dia' (Crowell 1979:97)

Com verbos "pontuais", como 'ir' e 'atirar', o estativo pode demonstrar um estado contemporâneo (cf. ex. 11) ou um estado resultante (cf. ex. 12).
(11) imedi
u-tu-nire
Cuiabá-të
homem 3sG-ir-ESTATIVO
Cuiabá-para
'o homem mudou-se para Cuiabá' (Crowell 1979:97)
(12) imedi
u-tu-re
Cuiabá-të
homem 3SG-ir-NEUTRO
Cuiabá-para

'o homem foi para Cuiabá'(Crowell 1979:97)

A mesma sentença pode ser interpretada como "O homem está (ou estava) indo para Cuiabá". O estativo tem o sentido de estado contemporâneo.

\section{Sobre o aspecto iterativo}

$\mathrm{O}$ aspecto iterativo difere dos outros aspectos pelo fato de poder ser selecionado tanto em orações imperativas, quanto em não-imperativas. Pode também ser selecionado em orações transitivas ou intransitivas. É realizado pela duplicação da raiz verbal e do pronome ligado a ela (Crowell 1979:102). 


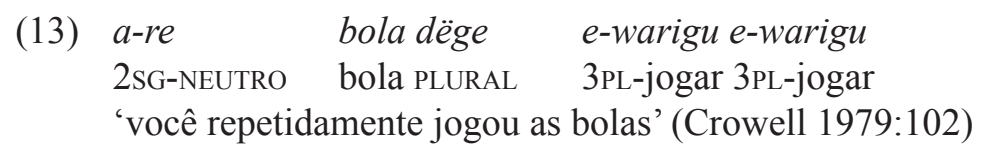

\section{Modo segundo Crowel}

Crowell argumenta que não fará a distinção das categorias de tempo, modo e aspecto, mas, faz a distinção entre modo nas orações independentes e dependentes.

Modo nas orações independentes

Segundo Crowell (1979:63), a seleção de dependente conduz a um sistema contendo o imperativo, o hortatório e o nulo.

Imperativo

O modo imperativo é realizado, em orações transitivas, por uma entonação imperativa e pela marca de aspecto imperativo - $b a$. As orações imperativas ocorrem quando o negativo é selecionado.
(14) $a-k a-r e$
karo bowije
2SG-NEGATIVO-NEUTRO peixe cortar
'você não cortou o peixe' (Crowell 1979:64)
(15) $a-k a-b a \quad$ karo bowije
2SG-NEGATIVO-IMPERATIVO peixe cortar
'não corte o peixe' (Crowell 1979:64)

Em orações intransitivas, o imperativo é possível somente quando as características negativo, intransitivo e segunda pessoa são selecionadas.

(16) a-pega-ka-ba!

2SG-Mau-NEGATIVO-IMPERATIVO

'não seja mau' (Crowell 1979:72)

\section{Hortatório}

Segundo Crowell, em vez do imperativo, pode ocorrer o hortatório, que é expresso por meio do morfema aspectual -wë 'propósito' (Crowell 1979:74)

(17) marigu pa-du-wë agora 1 PL=INCL.-ir-PROPÓSITO

'vamos agora' (Crowell 1979:74) 


\section{Declarativo}

Se nem o imperativo nem o hortatório é selecionado, mas sim o dependente, a construção será interrogativa ou declarativa (Crowell 1979:74).

\section{Interrogativo}

De acordo com Crowell (1979:74), a maior parte das perguntas é realizada por entonação. As perguntas do tipo sim/não podem receber o aspecto explícito, a saber $n a$, que segue imediatamente o elemento questionado. O aspecto explícito é sempre escolhido quando perguntas sim/ não são formadas por uma única palavra ou frase.

a-tu-re-na?

2SG-ir-NEUTRO-EXPLÍCITO

'você foi?' (Crowel 1979:75)

\section{Aspecto nas orações dependentes}

Em orações dependentes são selecionadas as noções aspectuais de propósito, de não-finito e de finito. Se o aspecto finito é selecionado, este conduz para o mesmo sistema de aspecto que seleciona declarativas independentes e orações interrogativas.

Propósito

O aspecto de propósito é marcado por meio da posposição bogai.

$\begin{array}{ll}\text { maragodi-re } & \text { dinheiro bogai } \\ \text { trabalhar-NEUTRO dinheiro PROPósITo } \\ \text { 'ele trabalhou por dinheiro' (Crowell 1979:107) }\end{array}$

Não-finito

A seleção de não-finito é independente de quais verbos sejam selecionados na oração. É realizado por $-i$ em posição ocupada por marcas de aspecto (Crowell 1979:106).

$$
\begin{array}{ll}
\text { e-ridiwa-re } & \text { u-i ipo kadë-di-dzi } \\
\text { 3PL-saber-NEUTRO } & \text { 3SG-NÃO-FINITO-pau.cortar-NOMINAL-REFERENTE } \\
\text { 'eles sabem que ele está cortando o pau' (Crowell 1979:106) }
\end{array}
$$

\section{Finito}

As orações finitas são identificadas como orações nominalizadas por $-d i$ 'nominal', que é o elemento final da oração dependente (Crowell 1979:105). 
(21) e-ridiwa-re u-nire ipo kadë-di-ji

3PL-saber-NEUTRO 3SG-ESTATIVO-pau-cortar- NOMINAL-REFERENTE

'eles sabem que ele estava cortando o pau' (Crowell 1979:105)

\subsection{Análise proposta por Viana}

Viana (2003a), por sua vez, considera que a língua Boróro apresenta as expressões de modo - imperativo, exortativo, interrogativo, declarativo - e as expressões de aspecto - (1) crença do falante (hipotético modi e nãohipotético Ø); (2) telicidade (télico neutro re, atélico estativo nire). Com base nessa distribuição, Viana (2003a) propôs o seguinte quadro:

\begin{tabular}{|c|c|c|}
\hline Modo & \multicolumn{2}{|c|}{ Aspecto } \\
\hline \multirow{2}{*}{$\begin{array}{l}\text { - Imperativo ba } \\
\text { - Exoratito wëë } \\
\text { - Interrogativo ba } \\
\text { - Declarativo } \\
\text { - Realis } \emptyset \\
\text { - Irrealis/Incerteza } r u\end{array}$} & (1) crença do falante & (2) telicidade \\
\hline & $\begin{array}{l}\text { - Hipotético medi } \\
\text { - Não hipotético } \emptyset\end{array}$ & $\begin{array}{l}\text { - Télico re (neutro) } \\
\text { - Atélico nire (estativo) }\end{array}$ \\
\hline
\end{tabular}

Quadro 2: Esquema modal e aspectual do Boróro (Viana 2003a).

\subsection{A análise proposta por Nonato}

Segundo Nonato (2008:112), a língua Boróro apresenta os morfemas de tempo, negação e modo "...aglutinados em núcleo funcional na ordem fixa que é mostrada no esquema". Nonato salienta que "...é gramatical a combinação entre os morfemas passíveis de aparecer em cada uma das três posições, o que gera 16 possibilidades $(2 \times 2 \times 4)$ ".

\begin{tabular}{|l|l|l|}
\hline $\begin{array}{l}\text { modi 'futuro' } \\
\emptyset \text { 'não futuro' }\end{array}$ & $\left\{\begin{array}{l}k a \text { 'negativo' } \\
\emptyset \text { 'positivo' }\end{array}\right.$ & $\left\{\begin{array}{l}r e \text { 'assertivo' } \\
j e \text { 'reportativo' } \\
w o \text { 'desiderativo' } \\
i e \text { 'infinitivo' }\end{array}\right.$ \\
\hline
\end{tabular}

\section{Tempo}

Segundo Nonato (2008:110), Boróro marca morfologicamente apenas a distinção entre tempo futuro (modì) e tempo não-futuro $(\emptyset)$ (cf. exemplos 22 e 23$)$. 


$\begin{array}{llllll}\text { (22) } & \text { e } & \text { Wogi } & \emptyset & \text { re } & \text { jice } \\ \text { 3PL pescar } & \text { NÃO-FUTURO } & \begin{array}{l}\text { ASSERTIVO lá } \\ \text { "eles pescaram lá/eles pescam lá' (Nonato 2008:111) }\end{array} \\ \text { (23) } & \text { e } \quad \text { wogi } & \text { modi } & \text { re } & \text { jice } \\ & \text { 3PL pescar } & \text { FUTURO } & \text { ASSERTIVO lá } & \text { lá } \\ & \text { 'eles vão pescar lá' (Nonato 2008:111) }\end{array}$

\section{Modo}

\section{Modo assertivo}

O modo assertivo é marcado pelo morfema -re e, de acordo com Nonato, "é o modo mais comum nas orações livres (cf. 24a), mas também pode ser empregado em orações subordinadas (cf. 24b). Indica uma asserção simples". Conferir exemplos reproduzidos com a mesma numeração do autor.
(24a) boe
e
wogi
bororos 3P pescar ASSERTIVO
re
'os bororo pescaram' (Nonato 2008:112)
(24b)
a-ridi-re
[boe e wogi re]
diji
2s.ver.ASSERT [bororo 3P pescar ASSERT] 'que'.TEMA
'você viu que os bororo pescaram?' (Nonato 2008:112)

\section{Modo reportativo} (2008:113)

O modo reportativo é marcado pelo morfema ie, segundo Nonato ...é empregado sobretudo em orações subordinadas com verbos quotativos (cf. 25a), mesmo quando se trata se uma afirmação do próprio falante (cf. 25b) mas também pode ser empregado numa oração livre, ficando subentendido que se trata de uma asserção de alguma pessoa (cf. 25c)."

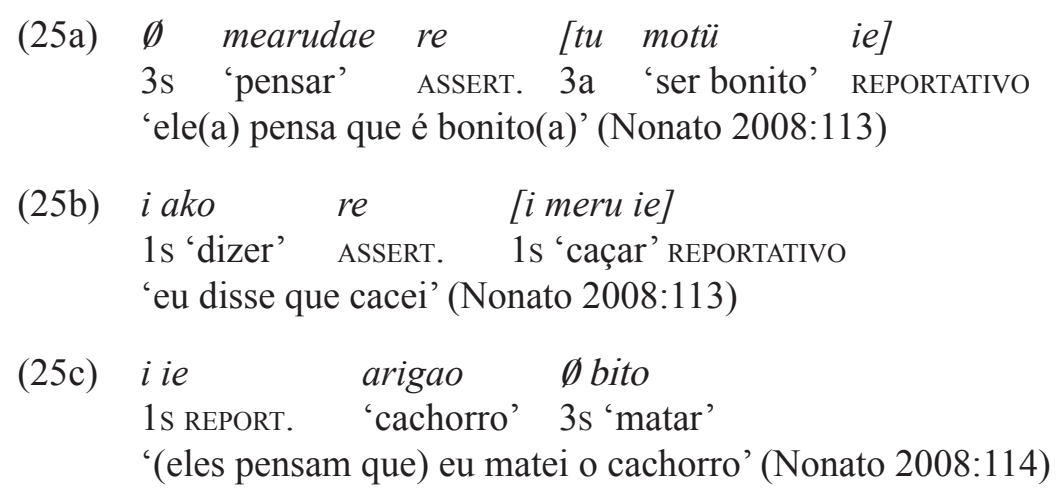




\section{Modo desiderativo}

É empregado em orações subordinadas ou principais que expressam desejo ou propósito, como complemento adverbial de propósito ou como exortativo (Nonato 1008:112). É marcado pelo morfema wo.

(26a) ( $i$ aidü re) $i$ kigurudu wo

(1s 'querer' ASSERT.) 1s 'urinar' DESIDERATIVO

'eu quero urinar' (Nonato 2008:114)

(26b) $p a$ tu wo pa bai kae

1 PI 'ir' DESID. 1PI 'casa' 'para'

'andemos para nossa casa' (Nonato 2008:115)

\section{Modo infinitivo}

É o modo “...usado apenas em orações subordinadas, dando à oração um sentido de processo geral visto como um todo" (Nonato 2008:113). De acordo com Nonato (idem), o modo infinitivo só é compatível com a negação. É marcado com o morfema -i.
ta.jorudu.re
[i wogi
i pobu
$\emptyset$. bagai dü].ji
2P.'ver'.ASSERT. [1s 'pescar' INF. 'pacu' 3s. 'por' 'que'].TEMA
'você me viu pescar' (Nonato 2008:115)

\section{Aspecto}

Nonato (2008) reconhece quatro marcas aspectuais na língua Boróro: (i) aspecto progressivo - $n u$ (cf. exemplo 28a); (ii) aspecto habitual kigodu (cf. exemplo 28b); (iii) aspecto incoativo gödu (cf. exemplo 29) e (iv) aspecto iterativo tratado mais especificamente abaixo.
(28a) $i \quad$ tu $k a$ dü nü re
1s 'ir' 'não' 'que' PROGRESSIVO ASSERTIVO
'eu não vou mais' (Nonato 2008:122)

(28b) $i \quad k a \quad d \ddot{u} \quad$ kigod $\ddot{u} \quad k a \quad$ re $\quad$ karo $\emptyset \quad k o$ $1 \mathrm{~s}$ 'não' 'que' 'sempre' 'não' ASSERT. 'peixe' 3s 'comer' 'eu nem sempre como peixe' (Nonato 2008:124)

(29) meri $\emptyset$ rekodü gödü re

sol 3s 'ir' INCOATIVO ASSERTIVO

'o sol está começando a ir’ (Nonato 2008:69) 
Nonato (2008:132) identifica a reduplicação verbal como atribuindo aspecto iterativo à ação expressa na sentença. Nonato apresenta apenas um exemplo reproduzido abaixo.

(30) boe re boe $\emptyset$ tügu woe

'bororos' ASSERT. 'coisas' 3s

'as pessoas sempre plantam aqui' (Nonato 2008:132)

\section{A minha proposta}

As análises sobre as categorias de modo, modalidade e aspecto na língua Boróro, como visto na seção anterior, são muito distintas. Não há entre os linguistas que pesquisaram a língua consenso na interpretação dos morfemas que carregam essas noções aspectuais e modais. Nesta seção, apresento uma nova interpretação para esses morfemas, com base em dados de Crowell (1979) e de Camargos e Rodrigues (2008), coletados em trabalhos de campo.

\subsection{Tempo}

A língua Boróro, assim como a maioria das línguas do tronco MacroJê, não apresenta a categoria de tempo marcada morfologicamente. Uma sentença como $i$ tu re pode ser interpretada tanto como 'eu fui' quanto 'eu vou'. Nesse caso, a distinção entre passado e presente é identificada pelo contexto pragmático.

Comrie (1976:9) ressalta que muitas línguas não possuem uma categoria temporal gramaticalizada, mas, provavelmente, todas elas possuem uma referência temporal lexicalizada, isto é, adjuntos adverbiais que localizam a situação no tempo. Este é o caso da língua Boróro.

$\begin{array}{lllll}\text { (31) baragwato } & i & n \text {-ogwage pemega } & \text { mode } \\ \text { amanhã } & 1 \mathrm{SG} & \mathrm{R} \text {-comer } & \text { bem } & \text { IND.PROJ. }\end{array}$

'amanhã eu vou almoçar bem'

$\begin{array}{lllll}\text { (32) dzaudze } & i & \text { n-ogwage pemega } & \text { re } \\ \text { ontem } & 1 \mathrm{SG} & \mathrm{R} \text {-comer } & \text { bem } & \text { IND }\end{array}$

'ontem eu comi bem'

\subsection{Modo}

A análise que proponho para o Boróro identifica dois modos (i) o indicativo e (ii) o imperativo. O modo indicativo é marcado pelo morfema 
$r e$. Este morfema apresenta distribuição bastante ampla na língua, ocorrendo em predicados transitivos, intransitivos e interrogativos, tanto na afirmação quanto na negação. Os exemplos abaixo apresentam dados em orações afirmativas e em orações negativas.

- Com predicados transitivos:

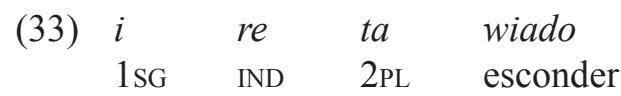

'eu me escondi de vocês'

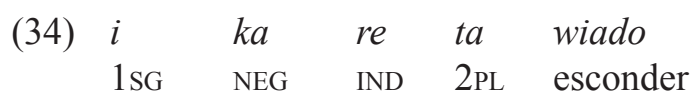

'eu não me escondi de vocês'

- Com predicados intransitivos:

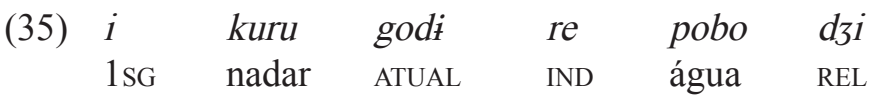

'eu nadei no rio'

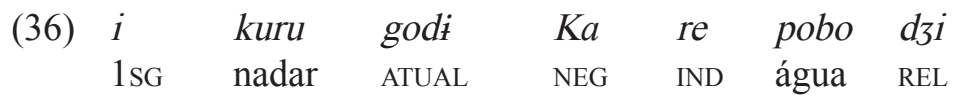

'eu nadei no rio'

- Com interrogativas:

(37) kaiba buti re

onde cair IND

'onde o menino caiu?'

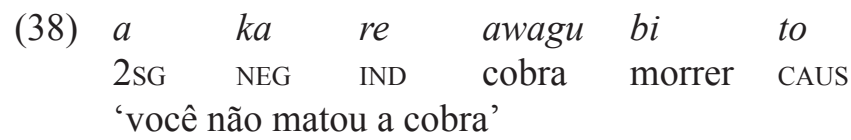

O morfema re pode aparecer também combinado com o morfema modi, caso em que se fundem na forma mode.

$\begin{array}{lll}\emptyset \quad \text { kodzari } & \text { mode } \\ \text { 3sG tossir } & \text { PROJ + IND } \\ \text { 'ele vai tossir' } & \end{array}$

Segundo Crowell (1979:90) a língua Boróro apresenta um sufixo mëdi (aspecto hipotético) que, em combinação com o sufixo re (aspecto neutro), resulta na forma -mëde. Compartilho com Crowell a ideia de que o morfema 
mëde, escrito por mim como mode, é resultado da fusão de modi + re, em enunciados afirmativos. Nas contrapartes negativas, entretanto, modi nunca se combina com re, uma vez que este morfema deve obrigatoriamente seguir a partícula de negação $k a$. A negação, como será mostrado adiante, revela com clareza que a análise de mode como amálgama modi + re é bem fundamentada. A minha hipótese encontra ainda reforço no padrão acentual da língua, o qual exclui a sequência forte-fraco-fraco em uma mesma palavra fonológica.

O Boróro possui um padrão acentual em que o acento primário recai sempre na penúltima sílaba da palavra. Viana (2003b:131) ressalta que o acento recai não somente na penúltima sílaba da palavra, mas categoricamente na penúltima sílaba da palavra fonológica: “(...) o acento é culminante, ou seja, cada palavra ou sintagma tem uma única sílaba comportando o acento principal e (...) o acento é ritmicamente distribuído, ocorrendo em intervalos regulares (de duas em duas sílabas a partir da penúltima)". Dessa forma, verifica-se que o padrão formado pelos dois morfemas modi e re ocasionaria um padrão acentual não permitido na língua [modire]. Vale ressaltar que o morfema re comporta-se como clítico, ou seja, desprovido de acento próprio. Como estratégia para manter o padrão da língua, tem-se um processo fonológico em que a vogal central $\dot{i}$ e a consonante $r$, que compartilha o traço $\mathrm{de}+$ soante com as vogais, sofrem um processo de queda. Assim, o resultado dessa fusão é a forma mode.

Como adiantei anteriormente, a forma modi é encontrada apenas na negação, uma vez que o morfema re fica separado de modì pelo morfema ka (negação). Note-se que, em posição final, o morfema re tende a cair na fala de algumas pessoas.

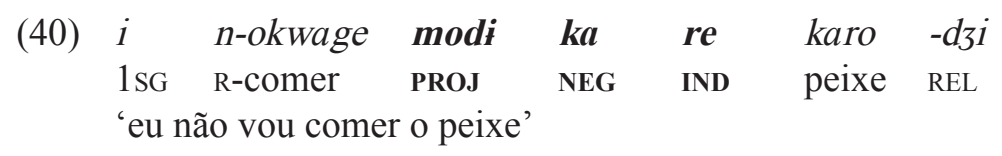

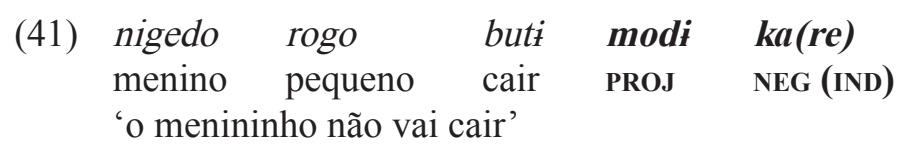

Segundo Palmer (1986:26), muitas línguas, se não todas, têm uma maneira clara de indicar que o falante está marcando uma afirmação que ele acredita ser verdadeira. É o sistema que Palmer chama de declarativo.

Dentro desse sistema declarativo é possível distinguir sistemas modais, tais como indicativo, subjuntivo e imperativo. Esses modos são, ainda segundo o autor, marcados por uma morfologia verbal. 
O modo indicativo indica tipicamente uma declarativa. Há uma tendência na linguística e na filosofia de tratar as declarativas como gramaticalmente ou logicamente simples, enquanto todas as outras são vistas como mais complexas e derivadas dela (Palmer 1986:27).

Nesta análise sobre a língua Boróro, utilizo o conceito de modo indicativo como um modo que indica uma declaração que não necessariamente tem ligação com os valores de verdade, daí porque excluí a possibilidade de chamá-lo de assertivo, termo fortemente marcado por valor de verdade. A noção de declaração relaciona-se simplesmente ao "ato ou efeito de declarar". Dessa forma, sentenças como 42, 43 e 44 são classificadas como declarações.

$\begin{array}{llllll}i & \text { mearida } & \text { re } & \text { aru } & \text { pemega } & \text { re } \\ \text { 1 } \mathrm{SG} & \text { pensar } & \text { IND dançar } & \text { bem } & \text { IND } \\ \text { 'eu acho que está dançando bem' } & & \end{array}$

$\begin{array}{lllllll}i & \text { mearitoru } & k a & \text { re } & \text { reru } & \text { re } & \text { dudzi } \\ \text { 1SG acreditar } & \text { NEG } & \text { IND } & \text { dançar } & \text { IND } & \text { 'que' } \\ \text { 'eu não acredito que ele está dançando' } & & \end{array}$

(44) $\emptyset$ reru $n \dot{i}$ re erigadi

3SG dançar PROG IND mesmo

'ele está dançado mesmo?'

Um dos fatos que contam positivamente para esta análise é o de que o modo indicativo é marcado sempre nas orações principais, enquanto nas construções equivalentes a orações subordinadas não se verifica a presença dessa marca modal, já que são meras nominalizações, como mostram os exemplos abaixo.

$$
\begin{aligned}
& i \text { tu mode [i n-ogwage wo] } \\
& 1 \mathrm{SG} \text { ir PROJ + IND 1SG R-comer NLZ } \\
& \text { 'eu vou almoçar' [eu vou para comer] }
\end{aligned}
$$

(46) $i \quad t-a j d u$ re $[i \quad n o d u$ wo $]$

$1 \mathrm{SG} \quad \mathrm{R}$-querer IND $1 \mathrm{SG}$ dormir NLZ

'eu quero dormir' [eu quero a minha dormida]

O outro modo encontrado na língua Boróro é o modo imperativo. Este contrapõe-se ao modo indicativo pela ausência de re. Trata-se do modo que marca os comandos. Diferentemente do modo indicativo em que as declarações não pressupõem mudanças ou interferências na conduta do receptor, no modo imperativo os enunciados têm como intenção promover 
alteração e/ou reação no comportamento do receptor, o que não significa que o comando dado será necessariamente executado.

Construções no modo imperativo podem receber partículas modalizadoras de comando, como a partícula do. Até o presente não foi possível identificar qual o real significado dessa partícula modalizadora, o que pretendo esclarecer futuramente.

$$
\begin{array}{lll}
a & \text { reru } & d o \\
\text { 2SG dançar } & \text { IMP } \\
\text { 'dança!' } &
\end{array}
$$

$\begin{array}{llll}a \quad \text { mago } & \text { podi } & d o \\ \text { 2SG falar } & \text { baixo } & \text { IMP } \\ \text { 'fala baixo!' } & \end{array}$

$$
\begin{aligned}
& \text { (49) a } \quad k \text {-ajmo } \emptyset \\
& \text { 2SG R-banhar IMP } \\
& \text { 'você pode banhar' }
\end{aligned}
$$

Diferentemente do modo indicativo, em que a negação é marcada pelo morfema $k a$, no imperativo a marca é $k a b a$, provavelmente resultante da combinação de um antigo morfema $k a$ com $b a$. De acordo com o "Dicionário Boróro-Português" (Ochoa 2005), kaba é uma variação da forma negativa $k a$ e é usada para formar o imperativo negativo dos verbos.

$\begin{array}{lllll}\text { (50) } & a & \text { kwage } & \text { kaba } \\ & \text { 2SG comer } & \text { NEG } & \\ & \text { 'não coma!' } & & \\ \text { (51) } & a & \text { mago } & \text { kuri } & \text { kaba } \\ & \text { 2SG falar } & \text { alto } & \text { NEG } \\ & \text { 'não fale alto!? } & & \end{array}$

\subsection{Modalidade}

O termo modalidade é considerado aqui como uma categoria nocional, modalizadora do discurso, cuja aplicação depende da escolha própria do falante.

Modalidade projetiva

Em Boróro toda ideia e/ou pensamento que se projeta para o momento posterior ao ato de fala, seja em oração afirmativa seja em oração negativa, é 
marcado pelo morfema modi. Como já mostrei anteriormente, a forma mode é resultado da combinação de modi e re.

(52) $i$ mearitoru barogwato $\emptyset$ aregodi mode meri kodi tabo 1SG acreditar amanhã 3SG chegar PROJ + IND sol partido com 'amanhã eu tenho certeza que ele vai chegar tarde'

Modalidade reportativa

A modalidade reportativa é marcada pelo morfema ie. Esse morfema corresponde ao "dizem que" do português, ao "hear say" do inglês.

Meriri Kurirew ako re $\emptyset \quad$ mugi ie Merúri pari kedze Meriri Kurirew dizer IND 3SG morar REP Merúri rumo em 'falaram que Meriri kurirew mora em Merúri'

\subsection{Aspecto ou Aktionsart (modalidade de ação)}

Em Boróro não há diferença entre aspecto e Aktionsart como as encontradas, por exemplo, em línguas europeias, em que essa diferença relaciona-se ao critério de mais ou menos gramaticalizado, ou como colocado por Desclés e Guentchéva (1997), mais ou menos transparentes.

O termo aspecto será aqui utilizado para designar tanto categorias aspectuais quanto Aktionsart. Neste trabalho, compartilho da ideia proposta por Comrie (1976:9) em que aspecto é considerado como uma categoria gramatical que pode ser expressa por meio de flexão ou por meio de perífrases.

Em Boróro, a distinção aspectual é feita por meio de morfemas.

Morfema ni 'progressivo'

$\begin{array}{llll}\text { (54) } & i \quad \text { vudi } \quad n i & \text { re } \\ \text { 1SG cair PROG } & \text { IND } \\ \text { 'eu estou caindo' } & \end{array}$

Morfema godi 'atual'

(55) $\emptyset$ rakitfaru godi re

3SG emagrecer ATUAL IND

'ele está emagrecendo'

Morfema kigodi 'habitual'

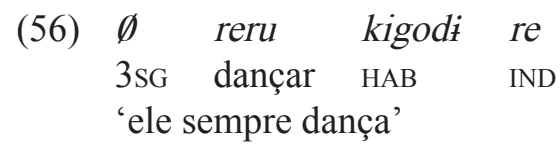


Morfema maj godi 'terminativo-recente

$\begin{array}{llllll}i & \text { re } & \text { adigo } & \text { bi } & \text { to } & \text { maj godi } \\ \text { 1SG IND } & \text { onça } & \text { morrer } & \text { CAUS } & \text { TER } \\ \text { 'eu acabei de matar essa onça' } & & \end{array}$

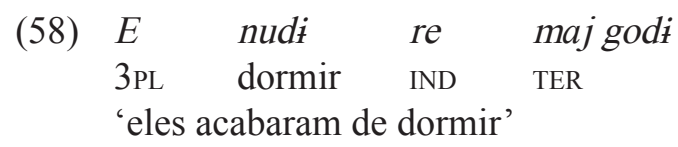

\section{Considerações finais}

Para Crowell e Viana o morfema modi, marca o aspecto hipotético, enquanto que Nonato o interpreta como um marcador temporal de futuro (em oposição a Ø'não-futuro'). Crowell não faz distinção entre tempo, modo e aspecto, enquanto que Viana faz distinção entre modo e aspecto e, neste último caso, distingue entre crença do falante e telicidade, incluindo no primeiro caso o hipotético modi (em oposição a Ø'não hipotético').

Com respeito ao morfema re, Crowell o vê como uma marca aspectual que ele rotula de "neutro" (em oposição a 'recente', 'incerteza', 'hipotético' e 'estativo'). Viana, por sua vez, além de tratá-lo também como marca aspectual e denominá-lo de 'neutro', considera-o télico (em oposição a nire 'estativo' e 'atélico'). Já Nonato, diferentemente dos demais, considera re um marcador de modo 'assertivo' (em oposição ao 'reportativo', 'desiderativo' e 'infinitivo').

Note-se que o morfema ie, que Nonato interpreta como marcador de modo 'reportativo', é identificado por Crowell como a contraparte de re em construções de discurso indireto, conforme exemplos abaixo.

(59) $u \quad$ tu $k a \quad r e$

$3 \mathrm{SG}$ ir NEG NEUTRO

'ele não foi' (Crowell 1979:91)

(60) $u$ tu $k a$ ie

$3 \mathrm{SG}$ ir NEG INDIRETO

('dizem que') 'ele não foi’ (Crowell 1979:91)

As demais diferenças podem ser comparadas no quadro abaixo. 


\begin{tabular}{|c|c|c|c|}
\hline & ASPECTO & MODO & MODALIDADE \\
\hline CROWELL & $\begin{array}{l}\text { Recente } \emptyset \\
\text { Incerto -ru } \\
\text { Neutro -re } \\
\text { Hipotético modi } \\
\text { Estativo nire } \\
\text { Iterativo duplicação } \\
\text { da raiz verbal e } \\
\text { do pronome ligado a ela }\end{array}$ & $\begin{array}{l}\text { Orações dependentes } \\
\text { Imperativo - ba } \\
\text { Hortatório -wëe } \\
\text { Declarativo } \\
\text { com entonoação } \\
\text { Interrogativo na } \\
\text { Orações independentes } \\
\text { Propósito bogai } \\
\text { Não-finito - } i \\
\text { Finitas -di }\end{array}$ & \\
\hline VIANA & $\begin{array}{l}\text { Hipotético medi } \\
\text { Não hipotético } \emptyset \\
\text { Télico re (neutro) } \\
\text { Atélico nire (estativo) }\end{array}$ & $\begin{array}{l}\text { Imperativo } b a \\
\text { Exortativo wëe } \\
\text { Declarativo realis } \emptyset \mathrm{e} \\
\text { irrealis/incerteza } r u\end{array}$ & \\
\hline NONATO & $\begin{array}{l}\text { Progressivo } n u \\
\text { Habitual kigodu } \\
\text { Incoativo gödu } \\
\text { Iterativo com } \\
\text { reduplicação da raiz }\end{array}$ & $\begin{array}{l}\text { Infinitivo } i \\
\text { Reportativo ie } \\
\text { Assertivo re } \\
\text { Desiderativo wëë }\end{array}$ & \\
\hline CAMARGOS & $\begin{array}{l}\text { Progressivo } n \dot{ } \\
\text { Atual godi } \\
\text { Habitual kigodi } \\
\text { Terminativo-recente } \\
\text { maj godi }\end{array}$ & $\begin{array}{l}\text { Indicativo re } \\
\text { Imperativo } \emptyset \text { ou } d o\end{array}$ & $\begin{array}{l}\text { Deôntica: } \\
\text { Projetiva modi } \\
\text { Epistêmica: } \\
\text { Reportativa ie }\end{array}$ \\
\hline
\end{tabular}

Quadro 3 - Comparação das análises de

Crowell (1979), Viana (2003b), Nonato (2008) e Camargos (2010) sobre as categorias de modo, modalidade e aspecto

A análise em desenvolvimento aqui apresentada sobre as manifestações de aspecto e de modalidade em Boróro se fundamenta em critérios distribucionais e no conhecimento que se tem das implicações de escolhas na identificação das reais funções de morfemas funcionais nas línguas estudadas. No caso do Boróro, a análise de que mode contém re acende uma luz para a interpretação do morfema re como sendo realmente um morfema modal, portanto de categoria distinta do morfema modi, uma vez que co-ocorre com este último. Evidência para isto é a negação em que os dois morfemas 
ocorrem claramente independentes. Quanto à semântica de re, atribuir-lhe um significado de modo declarativo é coerente com a ocorrência do morfema re com palavras que expressam dúvida ou que qualificam o grau de certeza do que é dito, inclusive com o reportativo ie. Ora, considerar re e ie como expressões de modo seria admitir que dois modos podem associar-se a um mesmo predicado, o que é impossível, já que diferentes modos correspondem a diferentes mundos, que nunca se misturam.

Considerar re uma marca de aspecto seria admitir sua onipresença em qualquer outra realização aspectual. A análise de modi como modalidade não impede que co-ocorra com expressões de modalidade, e com expressões de aspecto e de modo. Por todo o exposto, considero que a análise de re como marca do modo indicativo e modi como marca de modalidade projetiva é plenamente sustentada pelos dados da língua.

\section{Referências}

Albisetti, Cesar, Venturelli, Ângelo Jayme. 1962. Enciclopédia Bororo I. Vocabulário e etnografia. Campo Grande: Museu Regional Dom Bosco.

Albisetti, Cesar. 1969. Enciclopédia Bororo II. Lendas e antropônimos. Campo Grande: Museu Regional Dom Bosco.

Albisetti, Cesar. 1976. Enciclopédia Bororo III. Textos dos cantos de caça e pesca. Campo Grande: Museu Regional Dom Bosco.

Comrie, Bernard. 1976. Aspect: an introduction to the study of verbal aspect and related problems. Tokyo: Mugishobo.

Chung, Sandra, Alan Timberlake. 1992. Tense, aspect, and mood. In: Language typology and syntactic description, ed. by Timothy Shopen. Cambridge: Cambridge University Press.

Crowell, Thomas H. 1979. A grammar of Bororo. Ph. D. dissertation, Cornell University.

Desclés, Jean-Pierre, Zlatka Guentchéva. 1997. Aspects et modalités d'action (représentations topologiques dans une perspective cognitive), Etudes cognitives 2, Varsovie: Académie des Sciences de Pologne, pp. 145-175.

Jespersen, Otto. 1924. The philosophy of grammar. London: G Allen \& Unwin.

Nonato, Rafael Bezerra. 2008. Ainore Boe egore: um estudo descritivo da língua bororo e consequências para a teoria de caso e concordância. Dissertação de mestrado, Universidade Estadual de Campinas. 
Rodrigues, Aryon Dall'Igna. 1986. Linguas brasileiras: para o conhecimento das línguas indigenas. São Paulo: Edições Loyola.

Palmer, F. R. 1986. Mood and modality. Cambridge: Cambridge University Press.

Viana, Adriana. 2003a. Tempo, aspecto e modo em Boróro. Pesquisa Linguística 7:30-47. Brasília: UnB.

Viana, Adriana. 2003b. Morfossintaxe da língua Boróro. Exame de qualificação, Universidade de Brasília (ms.)

Viana, Adriana. 2007. Dissimilação de sonoridade em Boróro: uma abordagem com base no princípio do contorno obrigatório. In: Aryon Dall'Igna Rodrigues e Ana Suelly Arruda Câmara Cabral (orgs.), Linguas e culturas Macro-Jê. Brasília: Editora Universidade de Brasília/FINATEC. 